\title{
Teaching Creative Thinking Skills with Laboratory Work
}

\section{Nur Khoiri, Slamet Riyadi, Ummi Kaltsum, Nathan Hindarto and Ani Rusilawati}

Physics Education Department, Universitas PGRI Semarang, Jl. Lontar No. 1 Semarang

E-mail: nurkhoiri78@gmail.com

\begin{abstract}
Research on figuring out the ways to teach creative thinking skills via learning processes has been carried out. One of the methods applied to be efficient to teach creative thinking skills is laboratory work. Laboratory work is an important process in learning physics since students tend to find it hard to understand physical concepts if they are only taught verbally. Students will understand better when they are given real life examples and are allowed to learn the concepts through the laboratory work, whenever possible. The research was conducted at SMAN 1 Bringin by employing the quasi-experiment pre-test - posttest control group design. Creative thinking skills were measured based on four indicators: flexibility, fluency, originality, and detail. Results show that laboratory work was suitable to improve students' fluent thinking ability with $77 \%$ students showing improvement, and it was also a fit to improve students' original thinking with $84 \%$ students showing improvement. The experiment class revealed a gain of 0.51 , taken from an average pre-test score of 45.64 compared to the average posttest score of 73.5, which is an increase of 27.86. Meanwhile, the control class resulted in a gain of 0.40 , taken from an average pre-test score of 39.11 compared to the average post-test score of 83.44 , which is an increase of 24.33 .
\end{abstract}

Keyword : Creative thinking skills, Laboratory work

\section{Introduction}

There are certain skills required to survive the $21^{\text {st }}$-century society. These include digital skills, inventiveness, communication skills, and productivity. Fulfilling the demands in the 21 st century means that knowledge must also be supported by critical and creative thinking, utmost character, and the ability to make the most of the information technology [1].

Creative thinking is such an important skill to develop as it is not given from birth, but something that is gained, built and honed from learning to cooperate. Young people learn using all of their five senses. The creative thinking here is developed starting from the students themselves toward understanding the building blocks of science [2].

Laboratory work plays a role in the learning process of Physics as it helps materialize abstract concepts into real life experiences that students do themselves. According to Ausubel, laboratory work improves students' learning quality and their process skills such as measuring, observing, classifying and predicting [3]. Laboratory work is part of the learning process aimed at giving students an opportunity to test and apply theoretical facts using any tools and instruments available both inside and outside the laboratory. 
The process involved includes observing, measuring, and gathering data to be used to make proper analyses and hence, draw a conclusion [4].

Students learning physics will realize that there are many phenomena and each one of them has inherent problems that need to be solved using different kinds of ideas with the help of their teachers' guidance. A teacher does not only transfer knowledge, but also promote a learning environment that facilitates the development of collaborative and creative thinking skills. A teacher plays the role of a facilitator and a counselor [5]. A teacher's learning experience is transformed to the learner and results in a more meaningful learning experience. In a case study of maintaining creativity and innovation, it is said that students need to be directly involved in the learning process so that that learning process results in a meaningful learning experience of creative thinking [6]. A laboratory experiment has a vital role in helping students to understand concepts and develop other soft skills with the processes involved in an experiment [7]. Current use of laboratories in schools is not optimum as most laboratories are not in prime condition. Therefore, there is a need for a special preparation that will make laboratories ready for their utmost use. This is of necessity as inadequate laboratories also discourage teachers to use experiments in the teaching of science.

Those descriptions above show the importance of developing students' creative thinking skills using laboratory work. Laboratory work comes with inspirational processes of observing, formulating a problem, planning an investigation, conducting an experiment, using instruments to collect data, analyzing data, finding answers, making predictions, and communicating the results. Therefore, students are challenged to develop their fluent thinking, flexible thinking, original thinking, and detailed thinking and also other skills required in the process of creative thinking, i.e. preparation, incubation, illumination, and verification. Hence, students can develop their creative thinking skills [8][9]. This is only true as laboratory work is an effective method to obtain this learning goal [3].

In the process of physics learning, laboratory activity is one of the important activities for students to do, because the lab has a role to form learners' understanding and experience in the learning process, if we see physics as a product, their understanding is formed based on what they learn. When physics is seen as a process, it relates to the learners' experience of how to learn it; Which followed the emergence of a scientific attitude [10].

\section{Method}

The research was carried out in SMA Negeri 1 Bringin in Semarang regency in the second semester of the 2016/2017 academic year, from 7 - 27 March 2017. It is an experimental research using Quasi Experimental Design, of which the "Pre-test and Post-test Control Group Design" type was used. The samples were grade XI IPA 3 students as the experiment class using laboratory work and grade XI IPA 1 students as the control class using lectures. 
The instrument used to measure creative thinking was a seven-problem essay test, with the other instrument being an observation sheet to record students' creative thinking skills during learning. Creative thinking skills were measured from four aspects of fluent thinking, flexible thinking, original thinking, and detailed thinking. Analyses of the final data involved analyzing observation sheets of creative thinking with both $t$ test and gain test.

\section{Result and Discussion}

All problems in the creative thinking test are categorized as good, valid, and reliable. In the beginning, students have the same level of creative thinking skills. Data analyses of creative thinking skills using pre-test show that students of the control class with lectures and students of the experiment class with laboratory work have normally distributed and homogeneous data. Results of analyses for creative thinking skills are given in Table 1.

Table 1. Observation results of creative thinking skills aspects for both experiment and control classes.

\begin{tabular}{cccccc}
\hline & & \multicolumn{4}{c}{ Percentage } \\
\cline { 3 - 6 } No & & \multicolumn{2}{c}{ Control } & \multicolumn{2}{c}{ Experiment } \\
\cline { 2 - 6 } & Creative thinking & Meeting 1 & Meeting 2 & Meeting 1 & Meeting 2 \\
& indicator & $(\%)$ & $(\%)$ & $(\%)$ & $(\%)$ \\
\hline 1 & Fluent thinking & 57 & 63 & 69 & 77 \\
2 & Flexible thinking & 53 & 57 & 67 & 73 \\
3 & Original thinking & 50 & 53 & 65 & 69 \\
4 & Detailed thinking & 51 & 56 & 63 & 66 \\
\hline
\end{tabular}

Table 2. Test results of creative thinking skills aspects.

\begin{tabular}{clcc}
\hline No. & Creative thinking indicator & Control Class & Experiment Class \\
\hline 1 & Fluent thinking & $49 \%$ & $53 \%$ \\
2 & Flexible thinking & $61 \%$ & $68 \%$ \\
3 & Original thinking & $66 \%$ & $84 \%$ \\
4 & Detailed thinking & $57 \%$ & $59 \%$ \\
\hline
\end{tabular}

Analyses results of creative thinking data show that overall, creative thinking skills of students of the experiment class is higher than that of the control class. Creative thinking skills among students are revealed from observation sheets and scores from both pre-test and post-test. Analyses results of observation sheets indicate that creative thinking skills of students of the experiment class are better than that of the control class. Results of tests from all indicators also show that creative thinking skills among students of the experiment class are more dominant for all indicators. There are four indicators of creative thinking skills that become the focus of this research. They are shown in both Table 1 and Table 2. Learning activities with laboratory work strongly promote creativity among students. This creativity stems from the four research indicators of fluent, flexible, original, and detailed thinking. 
Observation instruments show that fluent thinking improved significantly in the experiment class, from $69 \%$ to $77 \%$, and $8 \%$ increase, while detailed thinking has the lowest improvement, at $3 \%$. The earlier figure is because that experimental instruments trigger students to be skillful in conducting experiments, as stages of the experimental process are known earlier. Meanwhile, the latter figure owes to the nature of students who tend to rush in doing the work and explaining every phenomenon experienced during the laboratory work learning. The feedback from students for this was that they were not given enough time to carry out their experiments.

Test results for the four indicators of creative thinking reveal that original thinking has the highest score in the experiment class, at $84 \%$. This is indicated by the fact that students discuss the problems given to them using their preferred language. On the other hand, fluent thinking is the lowest scorer with 53\%.

The interesting fact is that based on observation results, fluent thinking has the highest score, but then become the worst scorer, when seen from test results. A probable explanation is that while doing the test, the student had difficulties in explaining the results of their discussion.

Table 3. Results of gain test for students' creative thinking.

\begin{tabular}{cccccc}
\hline \multirow{2}{*}{ Class } & \multirow{2}{*}{ Number } & \multicolumn{3}{c}{ Mean } & \multirow{2}{*}{ Note } \\
\cline { 3 - 5 } & & Pre-test & Post-test & Gain $(g)$ & \\
\hline Control & 36 & 38.91 & 63.44 & 0.40 & Medium \\
Experiment & 36 & 45.63 & 73.5 & 0.51 & Medium \\
\hline
\end{tabular}

It can be seen in Table 3 that the experiment class yields a gain of 0.51 , as evident with an average pre-test score of 45.63 and an average post-test score of 73.5 , an increase of 27.87. Meanwhile, the control class has a gain of 0.40 , as evident with an average pre-test score of 38.91 and an average post-test score of 63.44, an increase of 24.53. Despite the fact that gains from both classes are in the medium category, the gain obtained from the experiment class using laboratory work is higher than the one from the control class using lectures. The factor affecting these two results is the different treatments given to the experiment class and the control class [1][10]. Therefore, this research has proven an alternative hypothesis that there is an effect of teaching method using laboratory work on the creative thinking skills among grade XI students involved in this research. The topic discusses static fluids with the sub-topic discussing the Archimedes law.

\section{Conclussion}

The method of laboratory work learning has positively influenced the creative thinking skills of students in SMA Negeri 1 Bringin. This learning method challenges students to maximize their creative potentials. 


\section{References}

[1] Susilawati, Sigit R and Khoiri N 2015 Jurnal Pendidikan Fisika Indonesia 11 (1) 73-83

[2] Ai-Girl T and Lai-Chong L 1991 Creativity for Teachers: Teaching and Learning Series (Singapore: Marshall Cavendish International)

[3] Nadia S, Sunaryo and Iswanto B H 2014 Prosiding Fisika 196-200

[4] Wulandari V C P Masjhudi and Balqis 2014 Jurnal Pendidikan Hayati 2 (2) 1-8.

[5] Korte L E 2014 Collaborative and Creative Thinking Skill Development Through the Design of Wearable Technologies Walden University Scholar Works 1-239

[6] Cheng M Y V 2010 Asia-Pacific Forum on Science Learning and Teaching 111

[7] AAPT (American Association of Physics Teachers) 1998 American Journal of Physics 66 (6) 483-5

[8] Cheng M Y V 2004 Asia-Pacific Forum on Science Learning and Teaching Journals 58

[9] Awang H and Ramly I 2008 International Journal of Human and Social Sciences 31

[10] Tamir P 2005 Journal of Educational Measurement 11 (1) 25-33 